\title{
Territorial variation in mortality from causes amenable to medical care in Poland
}

\author{
Wiktoria Wróblewska' \\ ${ }^{1}$ Institute of Statistics and Demography, Warsaw School of Economics, Poland
}

Wróblewska W. Territorial variation in mortality from causes amenable to medical care in Poland. Ann Agric Environ Med. $2017 ; 24(3): 489-495$. doi: 10.5604/12321966.1233557

\begin{abstract}
Introduction and objective. This study examines the geographical variation of amenable mortality in Poland, focusing primarily on the role of health care resources at the level of administrative districts and regions, and selected area socioeconomic characteristics as explanatory factors. The concept was used of amenable mortality, based on the assumption that deaths from certain causes should not occur in the presence of timely and effective health care.

Materials and method. Standardized death rates (SDR) from causes considered amenable to health care and, separately, for ischaemic heart disease (IHD), were calculated for each of 379 districts (NUTS 4 level) in Poland in 1991-1995 and 2006-2010, using unit mortality data from the National Causes of Death Register. The analytical procedure involved spatial analysis of the distribution of amenable mortality rates, selection of explanatory variables and fitting multilevel regression models using area-level and regional-level characteristics.

Results. The results indicate that mortality from conditions which have become amenable to medical intervention has generally decreased in all districts of Poland in the past two decades. Considerable territorial variation in mortality can be observed. Since the 1990s, these differences have been reduced for IHD-related mortality and have increased for amenable mortality.

Conclusions. The presented analysis only partly confirms the correlation between variables reflecting the infrastructure of health care resources and the territorial variation in mortality from these two categories of causes of death. Significant correlations with variation in mortality are revealed for the number of primary care physicians (at district level) and the number of specialist practitioners (at regional level). However, after controlling for socioeconomic variables, such as education and low income, the effect of the health care infrastructure-related variables was considerably reduced. The multi-level models also revealed a substantial variation at the regional level, which implies that there are other unobserved contextual influences on amenable mortality at this level.
\end{abstract}

\section{Iey words}

Amenable mortality, spatial variations, socioeconomic covariates, health care resources, multilevel modelling

\section{INTRODUCTION}

The rates of avoidable mortality - premature deaths from a set of conditions that could have been avoided in the presence of timely and effective health care [1], and socio-economic differences in mortality from these causes - are higher in Poland and other countries of Central and Eastern Europe than in most industralised countries [2-6]. The usefulness of the koncept of avoidable mortality is based on the assumption that such causes of death are related to the functioning of health care which is widely Explorer [7-12].

Very little is known about territorial variation in avoidable mortality in Poland, and about the correlations between observable differences in mortality and health care levels. Analyses of regional variations in avoidable mortality in developed countries indicate a weak association of avoidable mortality with indices of health resources or the supply of health services $[7,11-16]$. A review of 11 studies on avoidable mortality [14] found that indices of health services poorly predict territorial variation in mortality from causes amenable to medical intervention. Another study described weak associations for the following variables: number of general

Address for correspondence: Wiktoria Wróblewska, Institute of Statistics and Demography, Warsaw School of Economics, Madalinskiego 6/8, 02-513 Warsaw, Poland

e-mail:wwrobl@sgh.waw.pl

Received: 29 April 2014; accepted: 26 November 2014; first published: February 2017 practitioners, number of hospital beds, number of beds in medical university hospitals, and number of beds in minor hospitals [15]. A large proportion of territorial variation in mortality resulting from conditions which have become amenable to medical intervention may be attributed to socioeconomic variables, such as education, socio-professional group or economic situation $[5,6,11,17-18]$.

The presented study investigates territorial variation in mortality from causes amenable to medical care in Poland. Avoidable causes of death are divided into two groups with regard to which part of the health care system they are addressed, namely: 1) those responding to medical interventions and therapeutic management classified as causes amenable to medical care (treatable conditions), and 2) those that can be avoided by actions other than direct medical services, i.e. by general prevention, are classified as preventable conditions [12]. The present analysis focuses on the former group (treatable conditions). The local level of provision of health resources was believed to be more adequate for measuring the role of the health care system in small-area variation in mortality amenable to medical care than in the case of preventable mortality.The causes of death classified as preventable mortality are more responsive to inter-sectoral health policies and general preventive activities and central, rather than local health policies. 


\section{OBJECTIVE}

The aim of this study is to assess mortality rates from causes amenable to medical care at the small-area level ofadministrative districts in Poland, and investigate correlations between these rates and existing disparities in health care resources at different administrative levels, while controlling for confounding variables such as socioeconomic and demographic factors.

\section{MATERIALS AND METHOD}

The mortality analysis was based on individual mortality data obtained from the official statistics of the Central Statistical Office for the periods 1991-1995 and 2006-2010. Agestandardised death rates (SDRs) were used to assess mortality levels by direct standardization using the age structure for 2010 in Poland as the standard.

The analytical units were 379 districts, which correspond to NUTS 4 units in 2010 (Nomenclature of Statistical Territorial Units). Analysis was also conducted at the regional level of 16 provinces (NUTS 2), each comprising between 12-42 districts. The choice of provinces as second-level units in the analysis was based, on the one hand, on the current administrative division of the country, and on the other, on the organizational structure of the Polish health care system which is compatible with this division.

Analysis of deaths from causes amenable to medical intervention employed the Nolte and McKee classification [12], except for deaths due to ischaemic heart disease (IHD), which were analysed separately (Supp. 1). The decision to separate deaths due to IHD was taken because of the finding of high rates of IHD-related deaths in Poland and observed territorial differences between IHD-related deaths and deaths from other causes [19]. The analysis consisted of three steps, commencing with an assessment of spatial correlation of amenable mortality at district level, followed by the selection of covariates and a multilevel regression analysis.

All data preparation and exploratory analyses were performed SAS v.9.3. Spatial analyses and graphic presentations employed GeoDa software v.0.9.5-I (available for free downloading from www.csiss.org). Shape files for districts in Poland were updated to match the 2010 data. Variable selection and multilevel analysis was conducted in SPSS v.21.

Spatial analysis. A preliminary analysis of spatial variation in mortality at district level consisted in testing for spatial autocorrelation, which enables the identification of clusters of districts with similar levels of indices of interest. Moran's I statistics of spatial autocorrelations were used in the form of Global Moran's I and Local Indicators of Spatial Association (LISA) [20]. Spatial autocorrelation was evaluated on the basis of mortality data in a given district compared to the rates in neighbouring districts. Two types of spatial weights matrix were used, namely, the queen contiguity matrix and the five nearest neighbour matrix.

Moran's I statistics indicated positive spatial autocorrelations both for death rates from conditions amenable to medical intervention and for death rates due to ischaemic heart disease (Tab. 1). The fact that similar values of the autocorrelation indices were obtained using different
Table 1. Moran's I statistic for global spatial autocorrelation in SDR

\begin{tabular}{lcccc}
\hline Spatial weights & \multicolumn{2}{c}{ Amenable mortality } & \multicolumn{2}{c}{ IHD } \\
\hline & $1991-1996$ & $2006-2010$ & $1991-1996$ & $2006-2010$ \\
\hline Queen contiguity & 0.363 & 0.409 & 0.578 & 0.528 \\
\hline Nearest neighbours $(k=5)$ & 0.353 & 0.388 & 0.561 & 0.514 \\
\hline$p<0.001$ for all results & & & &
\end{tabular}

contiguity matrices may indicate that cities possessing the status of a district do not interfere with the results when queen neighbourhood matrices are used, where contiguity is understood as any section, also of zero length, i.e. a point.

Results from LISA analyses (data not shown) confirmed the presence of autocorrelations at local level and the clustering of districts with similar death rates (positive association). However, the presence of similarly large clusters of districts of low mortality in both groups of causes of death was only seen in the Podcarpathian region of southern Poland, with the remaining clusters at particular levels of amenable and IHD-related mortality often failing to overlap. These results indicate that IHD-related mortality should be analysed as distinct from amenable mortality in studies at lower levels of administrative division.

Results from the spatial analysis indicated the necessity of incorporating the spatial pattern in further analyses and limited possibility for using classic regression (ordinary leastsquares regression, OLS) to study correlations [21]. Possible solutions included the use of spatial lag or spatial error models that incorporate spatial dependence, but the explanatory variables characterised the health care system at both the level of districts and larger administrative units, and it was decided that multi-level regression analysis would be used.

Explanatory variables. In line with the purpose of this study, the focus was on variables describing health care infrastructure at the level of districts and provinces and on socio-economic and demographic variables characterising districts.

Available data for districts served to form the initial set of explanatory variables, which comprised variables characterising health care resources, such as the number of primary care physicians (per 10,000 population) [1] the number of beds in general hospitals (per capita), and sociodemographic and economic variables, such as unemployment levels (percentage of total work force), salary levels (\% of the national average), level of deprivation of the population (\% of the population relying on social security), degree of urbanisation (\% of urban dwellers), number of elderly people (\% of population aged 60 years or more), number of university graduates $(\%$ of population 13 years old or older, with university degree). In view of the presence of 'island' cities with district status, data on the number of hospital beds were regarded as inadequately reflecting the actual situation, and this variable was dropped from the analysis.

Further selection of explanatory variables at district level was based on principal components analysis without rotation. Of the variables forming the first component, those with the highest eigen values were included in the further analyses, namely, the percentage of university graduates, the percentage of the population relying on social security and the percentage of urban dwellers. The second principal component consisted essentially of two variables: the number of primary care physicians (per 10,000 population) and the 
percentage of elderly people in the district population. As the death rates were standardised for the population age structure, further analyses included the variable pertaining to the number of primary care physicians.

Provincial level health care resources were represented by the following variables: number of beds in general hospitals (per 10.000 population), presence of a medical university hospital in the province (binary variable), number of specialists (per 10.000 population), and the total number of physicians (per 10.000 population). The variable 'total number of physicians' was eventually dropped in view of its multicollinearity with other variables.

The data were retrieved from official statistical publications, and in particular the Local Data Bank of Central Statistical Office (GUS) and Health Care Information Systems Centre (unpublished data)

Multilevel analysis. To assess the territorial distribution of standardized mortality from causes amenable to health care and from IHD, the linear mixed-effects models procedure in SPSS was used with restricted maximum likelihood estimation [22]. A two-level modelling approach was employed with districts as the units of analysis at the first level and provinces on the second level. With this approach, it was possible to assess the territorial variation of mortality with regard to the role of compositional effects, i.e. the impact of variables directly or indirectly influencing mortality rates in districts, and contextual effects, i.e. the impact of variables reflecting health care resources at provincial level [23].

The models were fitted in several consecutive steps. First, the intercept model (model 0) was fitted, without any explanatory variables. In the next step, the district-level variables pertaining to health care infrastructure (model 1 ) and the socio-economic variables (model 2) were added. Model 3 additionally included the variables pertaining to health care infrastructure at provincial level. The significance of each consecutive model was estimated by analysing changes in the value of the restricted Log Likelihood. The interclass correlation coefficient (ICC) was calculated for each model as the ratio of group-level error variance over the total error variance. The ICC is the proportion of the overall unexplained variance in amenable mortality between districts that can be attributed to 'administrative' district clustering into provinces. To improve numerical stability, all variables from the first (district) level were centred at the provincial means. This also allowed for a simple interpretation of the intercept as an estimate of amenable mortality and IHD mortality if all explanatory variables in districts are at the level of the mean [24].

\section{RESULTS}

In 2006-2010, deaths from causes amenable to medical care accounted for $10.7 \%$ of the overall number of deaths in Poland, and $6.6 \%-16.5 \%$ of deaths in individual districts, while deaths attributable to ischaemic heart disease constituted $5.4 \%$ of overall mortality and $1.6 \%-11.8 \%$ of deaths in individual districts. Compared to the 1991-1995 rates, standardised death rates were markedly lower in the great majority of districts. The mean ratio of SDR (in districts) for 20062010 to SDR for 1991-1995 was 0.80 (range: 0.54-1.35) for amenable mortality, and 0.64 (range: $0.30-1.72$ ) for IHD- related mortality. Mean annual rates of decrease in death rates were $1.4 \%$ for amenable mortality and $2.9 \%$ for IHD. A detailed analysis of the rate of change in mortality for individual districts revealed that districts with high IHDrelated mortality in the early 1990s experienced greater relative decreases in mortality than districts with lower baseline mortality, while for amenable mortality the trend was the reverse, with districts of higher baseline mortality experiencing less prominent decreases compared to those districts where baseline mortality was lower. As a result, between-district variation in IHD-related mortality was reduced, while differences in amenable mortality rates between districts increased.

Table 2 presents SDRs (per 100,000 population) and the ratio of mortality rates for provinces and districts belonging to particular provincess. These results indicate high territorial variation in the two categories of mortality. Districts with the highest mortality rates in the period 2006-2010 had 2.5 times higher SDRs than districts with the lowest amenable mortality, and 4.5 higher SDRs in the case of IHD-related mortality. For the middle $50 \%$ of districts, absolute differences expressed as the interquartile (IQ) range were much lower, with SDRs of 106-129 for amenable mortality and 52-74 for IHD.

The spatial distribution of amenable and IHD-related mortality in Poland is shown in quartile maps for SDRs (Fig.1). The region with the lowest mortality from both causes is the Podcarpathian province south-eastern Poland. The districts with the highest IHD-related mortality form a distinct cluster in the south of Poland in the Silesian and Małopolska provinces, while the highest amenable mortality was recorded in districts from central Poland (Łódz province) and in the Warmin-Mazurian and Western Pomeranian provinces.

The results of the multilevel models presented in Tables 3 and 4 indicate a weak association between death rates and health care infrastructure, represented by the number of primary care physicians at district level. This variable was significantly related only to amenable mortality, and when the socio-economic variables were incorporated in the model, its effect was markedly reduced and was practically non-significant. Differences in SDR between districts are significantly influenced by socio-economic covariates. A higher proportion of population holding university degrees (the variable 'higher education') is associated with lower amenable and IHD-related mortality, and a higher degree of population deprivation, represented by the proportion of the population relying on social security (the variable 'social support'), contributes to higher amenable mortality rates. For IHD-related mortality, the variable 'social support' was not significant. A positive regression coefficient for the urbanisation index may confirm the finding of slightly higher mortality among urban vs. rural dwellers in some regions of Poland.

The interclass correlation coefficients (ICC) indicate that a large proportion of the variation in mortality between districts can be attributed to regions (voivodeships), which constituted the second level of the analysis, and to contextual factors associated with district clustering. The incorporation of regional variables in the next step of the analysis (Model 3) reduced theimportance of regional variation in mortality; however, the level of ICC remainedhigh, indicating the presence of other determinants not incorporated in the model. 
Table 2. Mortality from causes amenable to health care and from IHD by voivodeship and district in Poland, 2006-2010 and relative changes (1991-1995) - (2006-2010)

\begin{tabular}{|c|c|c|c|c|}
\hline \multirow[t]{2}{*}{$\begin{array}{l}\text { Region (NUTS2) } \\
\text { (number of districts) }\end{array}$} & \multicolumn{2}{|c|}{$\begin{array}{c}\text { SDR by region }^{\mathrm{a}} \\
\text { (range of variation by districts) }^{\mathrm{b}}\end{array}$} & \multicolumn{2}{|c|}{$\begin{array}{c}\text { Ratio } \\
\mathrm{SDR}_{06-10} / \mathrm{SDR}_{91-95} \\
\text { Mean (min-max) by districts }\end{array}$} \\
\hline & Amenable mortalityc & IHD & Amenable mortalityc & IHD \\
\hline Dolnośląskie (23) & $104.22(85.61-145.81)$ & $40.17(36.15-80.51)$ & $0.84(0.65-1.06)$ & $0.60(0.40-0.73)$ \\
\hline Kujawsko-pomorskie (24) & $112.67(103.32-143.15)$ & 52.15 (45.79-97.53) & $0.78(0.62-0.95)$ & $0.59(0.35-1.08)$ \\
\hline Lubelskie (24) & $99.56(86.16-123.65)$ & $39.00(24.177-75.09)$ & $0.70(0.57-0.94)$ & $0.49(0.29-0.71)$ \\
\hline Lubuskie (14) & $108.90(98.47-146.62)$ & $50.51(33.15-101.57)$ & $0.81(0.61-1.04)$ & $0.68(0.41-1.03)$ \\
\hline Łódzkie (24) & $121.64(102.73-149.75)$ & $45.28(43.56-103.32)$ & $0.83(0.70-1.08)$ & $0.71(0.44-1.56)$ \\
\hline Małopolskie (22) & $91.77(83.77-116.57)$ & 81.17 (63.90-97.56) & $0.77(0.64-1.27)$ & $0.94(0.64-1.72)$ \\
\hline Mazowieckie (42) & 110.06 (92.06-150.76) & 40.22 (36.80-89.98) & $0.81(0.59-1.13)$ & $0.71(0.37-1.34)$ \\
\hline Opolskie (12) & $105.27(94.31-142.792$ & 41.30 (30.94-71.76) & $0.65(0.57-0.75)$ & $0.41(0.28-0.51)$ \\
\hline Podkarpackie (25) & $83.46(81.01-133.27)$ & $38.04(36.43-75.54)$ & $0.67(0.54-0.81)$ & $0.48(0.34-0.74)$ \\
\hline Pomorskie (20) & $96.30(82.23-146.17)$ & 47.95 (37.53-80.39) & $0.83(0.65-1.25)$ & $0.55(0.37-1.56)$ \\
\hline Śląskie (36) & $125.59(97.45-172.00)$ & $73.02(48.43-145.26)$ & $0.77(0.63-0.93)$ & $0.61(0.42-0.85)$ \\
\hline Świętokrzyskie (14) & $105.66(94.03-133.11)$ & $50.76(35.65-86.03)$ & $0.81(0.62-1.07)$ & $0.80(0.53-1.21)$ \\
\hline Warmińsko-mazurskie (21) & $112.65(82.74-178.56)$ & $50.76(35.65-86.03)$ & $0.91(0.68-1.35)$ & $0.62(0.31-1.01)$ \\
\hline Wielkopolskie (35) & $110.13(101.95-149.57)$ & $43.59(34.55-79.45)$ & $0.87(0.68-1.14)$ & $0.63(0.38-0.97)$ \\
\hline Zachodniopomorskie (21) & $149.574(74.11-147.76)$ & $55.38(45.11-90.92)$ & $0.82(0.65-1.14)$ & $0.66(0.38-0.95)$ \\
\hline
\end{tabular}

a All amenable causes other than ischaemic heart disease.

b On the base of mortality data at region (voivodesips) in 2010

'On the base of mortality data at district level in 2006-2010

Table 3. Multi-level estimates for models of mortality of amenable to health care at district level, Poland 2006-2010

\begin{tabular}{|c|c|c|c|c|}
\hline & Model 0 & Model 1 & Model 2 & Model 3 \\
\hline & $\beta(S E)$ & $\beta(\mathrm{SE})$ & $\beta(S E)$ & $\beta(S E)$ \\
\hline \multicolumn{5}{|l|}{ Fixedeffects } \\
\hline Constant & $116,349(2,397)^{* * *}$ & $116,348(2,397)^{* * *}$ & $116,318(2.391)^{* * *}$ & $119,270(2.415)^{* * *}$ \\
\hline \multicolumn{5}{|l|}{ Level 1} \\
\hline Primary care physicians(per 10.000 population) & & $-0,797(0,385)^{*}$ & $\begin{array}{l}-0,041 \\
(0,343)\end{array}$ & $\begin{array}{l}-0,041 \\
(0,344)\end{array}$ \\
\hline Higher education & & & $-1,599(0,201)^{* * *}$ & $-1,599(0,201)^{* * *}$ \\
\hline Social support & & & $0,710(0,215)^{* * *}$ & $0,710(0,215)^{* * *}$ \\
\hline Degree of urbanisation & & & $0,187(0,035)^{* * *}$ & $0,187(0,035)^{* * *}$ \\
\hline \multicolumn{5}{|l|}{ Level 2} \\
\hline Number of specialists (per 10.000 population) & & & & $-2,584(1,343)^{*}$ \\
\hline Number of beds in general hospitals (per 10.000 population) & & & & $\begin{array}{c}1,061 \\
(0,512)^{*}\end{array}$ \\
\hline Presence of a medical university hospital & & & & $\begin{array}{c}9,377 \\
(4,462)^{*}\end{array}$ \\
\hline \multicolumn{5}{|l|}{ Randomeffects } \\
\hline \multicolumn{5}{|l|}{ Level 1} \\
\hline Constant & $194,954(14,465)^{* * *}$ & $193,203(14,355)^{* * *}$ & $137,147(10,233)^{* * *}$ & $137,156(10,235)^{* * *}$ \\
\hline \multicolumn{5}{|l|}{ Level 2} \\
\hline Constant & $82,863(33,26)^{*}$ & $82,929(33,257)^{* *}$ & $85,033(33,169)^{* *}$ & $58,534(26,332)^{* *}$ \\
\hline Interclasscorrelation & 0,299 & 0,300 & 0,383 & 0,299 \\
\hline Log likelihood & 3107,064 & 3102,857 & 2984,181 & 2968,639 \\
\hline DLog likelihood & & 4,207 & 122,883 & 138,425 \\
\hline$P$ & & & $P<0,001$ & $P<0,001$ \\
\hline
\end{tabular}

Note: ${ }^{*} p<0.1,{ }^{* *} p<0.01,{ }^{* * *} p<0,001$ 
a. Mortality of amenable to health care

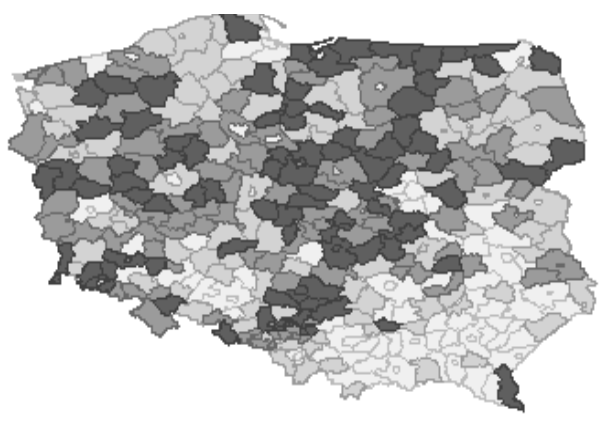

b. Mortality from ischaemic heart disease

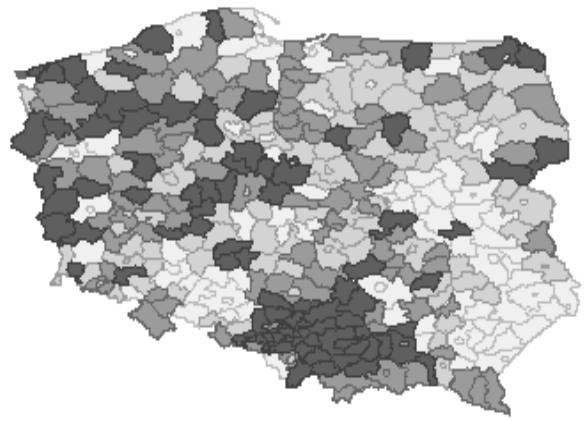

SDR Quantiles

$$
\begin{aligned}
& 1 \text { - Lowest SDR } \\
& 2 \\
& 3 \\
& 4 \text { - Highest SDR }
\end{aligned}
$$

\begin{tabular}{|c|c|c|c|c|}
\hline & Model 0 & Model 1 & Model 2 & Model 3 \\
\hline & $\beta(S E)$ & $\beta(S E)$ & $\beta(S E)$ & $\beta(S E)$ \\
\hline \multicolumn{5}{|l|}{ Fixed effects } \\
\hline Constant & $62,671(2,817)^{* * *}$ & $62,671(2,817)^{* * *}$ & $62,658(2,813)^{* * *}$ & $64,717(3,322)^{* * *}$ \\
\hline \multicolumn{5}{|l|}{ Level 1} \\
\hline Primary care physicians (per 10.000 population) & & $-0,263(0,381)$ & $0,416(0,366)$ & $0,416(0,366)$ \\
\hline Social support & & & $0,283(0.229)$ & $0,283(0.229)$ \\
\hline Degree of urbanisation & & & $0,149(0,037)^{* * *}$ & $0,150(0,037)^{* * *}$ \\
\hline \multicolumn{5}{|l|}{ Level 2} \\
\hline Number of specialists (per 10.000 population) & & & & $2,003(1.844)$ \\
\hline Number of beds in general hospitals (per 10.000 population) & & & & $0,251(0.703)$ \\
\hline \multicolumn{5}{|l|}{ Random effects } \\
\hline \multicolumn{5}{|l|}{ Level 1} \\
\hline Constant & $189,908(14,092)^{* * *}$ & $190,184(14,132)^{* * *}$ & $155,666(11,616)^{* * *}$ & $155,669(11,616)^{* * * *}$ \\
\hline \multicolumn{5}{|l|}{ Level 2} \\
\hline Constant & $118.052(46,023)^{* *}$ & $118.041(46,024)^{* *}$ & $119.327(45,973)^{* *}$ & $114.780(49,509)^{*}$ \\
\hline Interclasscorrelation & 0,383 & 0,383 & 0,434 & 0,424 \\
\hline Log likelihood & 3102,374 & 3101,989 & 3034,529 & 3021,664 \\
\hline$\Delta$ Log likelihood & & 0,385 & 67,845 & 80,71 \\
\hline$P$ & & & $P<0,001$ & $P<0,001$ \\
\hline
\end{tabular}

Figure 1. The spatial distribution of standardized mortality of (a) amenable to health care and (b) ischaemic heart disease in Poland, 2006-2010

Table 4. Multi-level estimates for models of mortality for IHD at district level, Poland 2006-2010

Note: ${ }^{*} p<0.1,{ }^{* *} p<0.01,{ }^{* * *} p<0,001$

The variables referring to health care resources at regional level were found to be associated with amenable mortality in districts. However, some correlations were not those that had been expected to occur. The findings confirmed the importance of availability of specialist medical care as higher numbers of specialist practitioners were associated with lower mortality at the district level. At the same time, regression coefficients for the number of hospital beds and the presence of a high-class specialist hospital (medical university hospital) in the province indicate higher amenable mortality in regions scoring higher on these scales. These results may indicate, on the one hand, that the territorial distribution of hospitals matches the demand for health services stemming from greater health care-related needs in a given administrative region and, on the other, that hospital beds are not used effectively in regions with a large number of hospital beds. In the model of IHD-related mortality, the variables referring to health care infrastructure at regional level turned out to be non-significant for predicting the observed differences in mortality between districts. 


\begin{tabular}{|c|c|c|c|}
\hline Cause of death & Age & ICD9 & ICD10 \\
\hline Intestinal infections & $0-14$ & 000-009 & A00-A09 \\
\hline Tuberculosis & $0-74$ & $010-018,137$ & A15-A19, B90 \\
\hline Other infectious diseases (Diphtheria, Tetanus, Poliomyelitis) & $0-74$ & $032,037,045$ & $A 36, A 35, A 80$ \\
\hline Whooping cough & $0-14$ & 033 & A37 \\
\hline Measles & $1-14$ & 055 & B05 \\
\hline Malignant neoplasm of colon and rectum & $0-74$ & $153-154$ & $\mathrm{C} 18-\mathrm{C} 21$ \\
\hline Malignant neoplasm of skin & $0-74$ & 173 & $\mathrm{C} 44$ \\
\hline Malignant neoplasm of breast & $0-74$ & 174 & C50 \\
\hline Malignant neoplasm of cervix uteri & $0-74$ & 180 & C53 \\
\hline Malignant neoplasm of testis & $0-74$ & 186 & C62 \\
\hline Hodgkin's disease & $0-74$ & 201 & C81 \\
\hline Leukaemia & $0-44$ & 204,208 & C91-C95 \\
\hline Diseases of the thyroids & $0-74$ & $240-246$ & E00-E07 \\
\hline Diabetes mellitus & $0-49$ & 250 & E10-E14 \\
\hline Epilepsy & $0-74$ & 345 & G40-G14 \\
\hline Chronic rheumatic heart disease & $0-74$ & $393-398$ & $105-109$ \\
\hline Hypertensive disease & $0-74$ & $401-405$ & $110-115$ \\
\hline Cerebrovascular disease & $0-74$ & $430-438$ & $160-169$ \\
\hline All respiratory diseases (excl. pneumonia/influenza) & $1-14$ & $460-479,488-519$ & J00-J09, J20-J99 \\
\hline Influenza & $0-74$ & 487 & J10-J11 \\
\hline Pneumonia & $0-74$ & $480-486$ & J12-J18 \\
\hline Appendicitis & $0-74$ & $540-543$ & K35-K38 \\
\hline Abdominal hernia & $0-74$ & $550-553$ & K40-K46 \\
\hline Cholelithiasis\& cholecystitis & $0-74$ & $574-575$ & K80-K81 \\
\hline Nephritis and nephrosis & $0-74$ & $580-589$ & N00-N07, N17-N19, N25-N27 \\
\hline Benign prostatic hyperplasia & $0-74$ & 600 & N40 \\
\hline Maternal deaths & All & $630-676$ & O00-099 \\
\hline Congenital cardiovascular anomalies & $0-74$ & $745-747$ & Q20-Q28 \\
\hline Perinatal deaths, all causes excluding stillbirths & All & $760-779$ & P00-P96, A33-A34 \\
\hline Misadventures to patients during surgical and medical care & All & E870-E876, E878-E879 & Y60-Y69, Y83-Y84 \\
\hline Ischaemic heart disease* & $0-74$ & $410-414$ & $120-125$ \\
\hline
\end{tabular}

* deaths due to ischaemic heart disease (IHD) were analysed separately

\section{RESULTS AND DISCUSSION}

The decreasing levels of mortality from causes amenable to medical care noted in most districts and across all regions since the beginning of the systemic transition, especially with regard to IHD-related mortality, testify to beneficial changes in population health, and indirectly point to improvements and progress in medical procedures, level of education of medical professionals, quality of medical services and organisation of the health care system in Poland. However, the detailed analyses intended to explain territorial variation in the two categories of mortality in terms of variables reflecting the infrastructure of medical resources and health care, found that these variables were only partially relevant.

The significance of the variable 'number of primary care physicians per 10,000population' indirectly confirms the importance of the tier of primary care and primary care physicians for the health status of the population, which is consistent with the findings of other studies of overall and cause-specific mortality [25-26]. Analysis of health care resources at regional (province) level points to the importance of easy access to specialists, which was represented by the variable 'number of physicians per 10,000 population' in this study. The higher number of specialists available, resulting in easier access to specialised diagnostic tests and services, may be associated with improved amenable mortality rates.

The nature of the classification of causes of death used in the presented study was not discussed, but small-area studies (spatial analyses) show that the choice of a definition can influence the spatial patterns of mortality identified in a study [27]. In the light of the current findings and the organisation hierarchy in the Polish health care system, it would be advantageous to use in future studies a division of amenable 
mortality into causes of death attributable to primary and specialized health care and interventions, i.e. according to the tier of the health care system (place of intervention) to which these conditions are responsive $[17,28]$.

Analysis confirmed the considerable importance of the level of education and deprivation of the population in small-area analysesas factors accounting for some of the variation in amenable and IHD-related mortality. Notably, after controlling for socioeconomic variables, the effect of the variables representing health care resources was reduced. The effect of the variable 'level of education' may manifest itself via such factors as earlier initiation of diagnostic testing or turning to specialist practitionersfor medical advice more frequently, as well as other immaterial resources that are more easily accessible to those with a higher social standing $[29,30]$.

The presented study, a preliminary investigation of territorial variation in mortality and its association with indices of health care resources, has several limitations which are mostly related to data availability issues. The indices of health care resources and supply of health services used in the study, such as the number of primary care physicians, number of specialist practitioners and the number of hospital beds, fail to grasp the essence of quality, availability and effectiveness of medical care. More reliable results could be produced with other indices of structure and organisation of health care, such as the availability and qualifications of physicians, patient waiting times, time management in health care institutions, hospital bed occupancy or existing medical procedures $[12,14]$. The presented analysis did not account for environmental and social covariates, such as climate, water quality, environmental pollution, regional cuisine, life style, leisure activities, or territorial gradients of historical origin whose ranges may not coincide with the borders of the administrative areas analysed. The presence of effects of such factors was indicated by the spatial autocorrelation data, which confirmed that mortality due to the causes analysed in the study was not spatially random, and that districts tend to cluster into groups with similar mortality rates. Further, more narrowly focused and in-depth studies of amenable mortality will doubtless aid the identification of social and environmental determinants of health status and mortality in Poland, and may contribute to improved adjustment of health policies and efforts undertaken within the health care system at regional and smaller-scale levels.

\section{Acknowledgements}

The study was financially supported by the National Science Centre (NCN) in Poland (Project No. 2011/01/B/HS4/04797) but the NCN was not involved in its design, data collection, findings or decision to publish.

\section{REFERENCES}

1. Rutstein D, Berenberg W, Chalmers T, Child C, Fishman A, Perrin E. Measuring the quality of medicalcare. N Engl J Med 1976; 294: 582-588.

2. Gay J, Paris V, Devaux M, de Looper M. Mortalityamenable to healthcare in 31 OECD countries: estimates and methodologicalissues. Paris, OECD, 2011.

3. Nolte E, Scholz R, Shkolnikov V, McKee M. The contribution of medical care to changing life expectancy in Germany and Poland. SocSci Med 2002; 55(11): 1905-1921.
4. Velkova A, Wolleswinkel-van den Bosch JH, Mackenbach JP. The east-west life expectancy gap: Differences in mortality from conditions amenable to medical intervention. Int J Epidemiol 1997; 26: 75-84.

5. Plug I, Hoffmann R, Artnik B, Bopp M, Borrell C, Costa G, et al.. Socioeconomic inequalities in mortality from conditions amenable to medical interventions: do they reflect inequalities in access or quality of health care?. BMC Public Health 2012; 12(1): 346. doi:10.1186/14712458-12-346.

6. Stirbu I, Kunst AE, Bopp M, Leinsalu M, Regidor E, Esnaola S, Costa G, Martikainen P, Borrell C, Deboosere P, Kalediene R, Rychtarikova J, Artnik B, Mackenbach JP.Educational inequalities in avoidable mortality in Europe. J Epidemiol Community Health 2010; 64(10): 913-920.

7. Charlton J, Hartley R, Silver R, Holland W. Geographicalvariation in mortality from conditionsamenable to medicalintervention in England and Wales. Lancet 1983; 1: 691-696.

8. Nolte E, McKee M. Measuring the health of the nations: how much isattributable to healthcare? Ananalysis of mortalityamenable to medicalcare. BMJ 2003; 327: 1129-1132.

9. Nolte E, McKee M. Measuring the health of nations: updating anearlier analysis. Health Aff 2008; 27: 58-71.

10. Mackenbach J. The contribution of medicalcare to mortalitydecline: McKeownrevisited. J ClinEpidemiol 1996; 19: 1207-1213.

11. Poikolainen K, Eskola J. The effect of health services on mortality: decline in deathrates from amenable and non-amenablecauses in Finland, 1969-1981. Lancet 1986; 1: 199-202.

12. Nolte E, McKee M. Doeshealthcaresavelives? Avoidable mortality revisited. London, The Nuffield Trust, 2004.

13. Carr-Hill RA, Hardman GF, Russell IT. Variations in avoidable mortality and variations in health care resources. Lancet 1987; 1: 1789-1792

14. Mackenbach JP, Bouvier-Colle MH, Jougla E. "Avoidable” mortality and health services: A review of aggregate data studies. J Epidemiol Community Health, 1990; 44(2): 106-111.

15. Mackenbach JP, Looman CW, Kunst AE, Habbema D, van der Maas PJ. Regional differences in decline of mortality from selected conditions: The Netherlands, 1969-1984. Int J Epidemiol 1988; 17: 821-829.

16. Tobias M, Yeh L. How much does health care contribute to health gain and to health inequality? Trends in amenable mortality in New Zealand 1981-2004. Aust N Z J Public Health 2009; 33(1): 70-78.

17. Lumme S, Sund R, Leyland A, Keskimäki I. Socioeconomic equity in amenable mortality in Finland 1992-2008. SocSci Med 2012;75(5): 905-913.

18. Westerling R, Gullberg A, Rosen M. Socioeconomic differences in 'avoidable' mortality in Sweden, 1986-1990. Int J Epidemiol 1996; 25: 560-567.

19. Wojtyniak B, Rabczenko D, Pokarowski P, Poznańska A, StokwiszewskiJ. Atlas of mortality in Poland, 2008-2010 [in Polish]. National Institute of Public Health - National Institute of Hygiene, Warsaw 2012.

20. Anselin L. Local indicators of spatial association-LISA. Geogr Anal 1995; 27: 93-115.

21. Anselin L, Griffith D. Do spatial effects really matter in regression analysis. Pap RegSciAssoc 1988; 65: 11-34.

22. Snijders T, Bosker R. Multilevel analysis. An introduction to basic and advanced multilevel modeling. 2nd ed. London, Sage, 2002.

23. Diez Roux AV. A glossary for multilevel analysis, J Epidemiol Community Health 2002; 56: 588-594.

24. Enders CK, Tofighi D. Centering predictor variables in cross-sectional multilevel models: A new look at an old issue. Psychol Methods 2007; 12: $121-138$.

25. Macinko J, Starfield B, Shi L. Primary care systems and health outcomes in Organization for Economic Cooperation and Development (OECD) countries. Health Serv Res 2003; 38(3): 831-865.

26. Continelli T, McGinnis S, Holmes T. The effect of local primary care physician supply on the utilization of preventive health services in the United States. Health Place 2010; 16(5): 942-951.

27. French KM, Jones K. Impact of definition on the study of avoidable mortality: Geographical trends in British deaths 1981-1998 using Charlton and Holland's definitions, SocSci Med 2006; 62(6): 1443-1456.

28. Simonato L, Ballard T, Bellini P, Winkelmann R. Avoidable mortality in Europe 1955-1994: A plea for prevention. J Epidemiol Community Health 1998; 52(10): 624-630.

29. Mackenbach JP. The persistence of health inequalities in modern welfare states: the explanation of a paradox. SocSci Med 2012; 75(4): 761-769.

30. Van Doorslaer E, Koolman X. Explaining income-related inequalities in doctor utilisation in Europe. Health Econ 2004: 13(7): 629-647. 